\title{
Recursos y constreñimientos del trabajo de los periodistas políticos en empresas informativas
}

Resources and constraints of the work of political journalists in information enterprises

GERARDO CABALLERO ROJAS

Licenciado en Periodismo y magíster en Sociología por la Pontificia Universidad Católica del Perú (PUCP). Es docente de la Facultad de Ciencias y Artes de la Comunicación del mismo centro de estudios. Tras 12 años de experiencia en el periodismo político, hoy se dedica a la comunicación política, que es precisamente uno de sus campos de interés, como también lo son los medios de comunicación y el uso de redes sociales digitales para la movilización social y los procesos políticos. 



\title{
Recursos y constreñimientos del trabajo de los periodistas políticos en empresas informativas
}

\section{Resources and constraints of the work of political journalists in information enterprises}

\author{
Gerardo Caballero Rojas \\ PONTIFICIA UNIVERSIDAD CATÓLICA DEL PERÚ \\ gerardo.caballero@pucp.edu.pe
}

\section{PALABRAS CLAVE / KEYWORDS}

Periodismo político / empresa informativa / medios de comunicación / periodismo / política

Political journalism / information enterprise / mass media / journalism / politics

\section{SUMILLA}

Este artículo describe cómo en el actual contexto mediático los periodistas políticos que trabajan en una empresa informativa reciben, de un lado, recursos materiales que los ayudan a realizar su trabajo pero, por otro lado, están sometidos a una serie de constreñimientos, los cuales hemos definido en dos tipos: corporativos, que están relacionados a la naturaleza empresarial capitalista del medio de comunicación, y editoriales, que están vinculados a simpatías o preferencias políticas. Para entender mejor estos recursos y constreñimientos se ha entrevistado a cuatro periodistas de la sección política de una empresa informativa peruana, quienes describen sus rutinas de trabajo.

\section{ABSTRACT}

This article describes how, in the current media context, political journalists who work in an informative company receive, on the one hand, material resources that help them to carry out their work but, on the other hand, they are subject to a series of constraints, which we have defined in two types: corporate constraints, which are related to the capitalist business nature of the media, editorial constraints, which are linked to political preferences or sympathies. To better understand these resources and constraints, we interviewed four journalists from the Politics section of a Peruvian information company, who describe their work routines. 


\section{Introducción}

Los periodistas tienen un rol socialmente legitimado e institucionalizado para construir la realidad social como realidad pública y socialmente relevante, $\mathrm{y}$ esta es una competencia que realizan al interior de aparatos productivos especializados, que son los medios de comunicación (Rodrigo Alsina, 1993).

Estos medios de comunicación no son otra cosa que empresas dedicadas a la producción de contenido informativo. Las empresas informativas son unidades económicas de producción y difusión de mensajes informativos con ánimo de lucro (Tallón, 1992). Si bien todas las empresas pretenden obtener el máximo de ganancias con la venta y la oferta de productos, los medios de comunicación elaboran productos que tienen una particularidad: a diferencia de enseres como los zapatos o electrodomésticos, afectan nuestra percepción del mundo y, en gran medida, nuestras acciones (López García, 2010).

La adscripción de los periodistas a las empresas informativas supone, a la luz de la sociología de las organizaciones, algunas consecuencias. Howard Becker (2008) sostiene que, en los distintos campos profesionales, las organizaciones brindan a los trabajadores recursos que les permiten llevar a cabo sus tareas. Por su parte, Gary Alan Fine (1992) mues- ponen constreñimientos o restricciones que dificultan a los trabajadores llevar a cabo un trabajo que puedan considerar de calidad.

En este artículo nos hemos propuesto reflexionar sobre los recursos y constreñimientos que supone a los periodistas la pertenencia a una empresa informativa. Específicamente, pondremos atención en los periodistas políticos, quienes elaboran aquellas informaciones a través de las cuales los medios de comunicación organizan y estructuran la conversación del público sobre la vida política, información que los ciudadanos necesitan para ser capaces de deliberar sobre política (Conaghan, 1997).

Para llevar a cabo el presente estudio, hemos decidido complementar este abordaje con entrevistas semiestructuradas realizadas a cuatro periodistas políticos, a quienes llamaremos "Andrés", "Gabriel”, "Francisco" y "Jessica”. Las entrevistas se realizaron entre junio y julio del 2017, cuando los cuatro periodistas eran parte de la sección política de una importante empresa informativa con sede en Lima, Perú, a la cual llamaremos "Universo".

"Universo" tiene una plataforma impresa y una plataforma online, y es parte de un conglomerado mediático que a fines del 2017 registraba un activo total de S/2541.62 millones. 


\section{El contexto mediático}

La Organización de las Naciones Unidas para la Educación, la Ciencia y la Cultura (Unesco) (2018) ha expresado que existen influencias políticas y económicas que impactan sobre los sistemas de medios. Entre las influencias políticas, se señalan la deslegitimación generalizada de los medios por parte de los actores políticos y los intentos de capturar los medios, que limitan o distorsionan la cobertura informativa. Entre las influencias económicas, la Unesco menciona la concentración de la propiedad de los medios y la transformación de los modelos de negocio, en la medida en que los medios de comunicación han tenido que redefinir dónde reside el valor de sus contenidos.

Precisamente, esta redefinición es la que ha marcado la suerte del periodismo en los últimos años. El modelo de negocio tradicional que durante décadas sostuvo a las empresas informativas ha entrado en crisis. Es abundante la literatura que demuestra que los ingresos por publicidad y venta de ejemplares han pasado a ser insuficientes para seguir sosteniendo a los medios de comunicación (Campos-Freire, Yaguache y Ulloa, 2017; Nafría, 2017; Díaz Nosty, 2017)

Esto ha llevado a la mayoría de los medios de comunicación a una búsqueda desesperada de audiencias más grandes, la cual ha precarizado el trabajo periodístico. Sergio Javier Valera García (2016) ha demostrado cómo en España esta obsesiva búsqueda de audiencia ha generado, entre otros efectos negativos, un proceso de banalización de la información, que consiste en que los contenidos informativos tiendan hacia lo banal, superficial o poco importante.

La elaboración de informaciones políticas no ha sido ajena a este contexto mediático. Nereida Carrillo (2013) ha señalado que lo inconsistente, lo banal y lo anecdótico está superando cada vez con más facilidad los filtros de lo noticioso, eludiendo los criterios de lo importante y dando lugar a lo que la autora ha llamado el "infoentretenimiento volátil".

Claudia Mellado Ruiz y sus colegas han mostrado que, entre 1990 y el 2010, el periodismo político en Chile ha pasado de un modelo cívico, que entiende al público como ciudadano, a un modelo de infoentretenimiento, que entiende al público como espectador de la política (Mellado-Ruiz, López-Rabadán y Elortegui, 2017).

Ello supone un riesgo para el sistema democrático, toda vez que el ejercicio del periodismo y la política han estado siempre intrínsecamente relacionados. Ya hace casi un siglo, Walter Lippmann observaba que muchas de las cosas que, desde el punto de vista político, las personas debían afrontar, sucedían más allá de lo que podían conocer por sus propios medios. La única forma de estar al tanto 
de los asuntos públicos, decía el autor estadounidense, era a través de los medios de comunicación (Lippmann, 2003).

En efecto, las democracias modernas están formadas de tal manera que el trabajo informativo de los medios de comunicación resulta esencial. Como afirma Denis McQuail (1996), vivimos en un mundo donde los procesos políticos y gubernamentales se basan en el supuesto de que sabemos lo que está ocurriendo a través de los medios de comunicación.

Kelly Robledo-Dioses señala que existe un "vínculo natural" entre el periodismo político y la democracia, pues el periodismo político cumple el rol de agente de conexión entre el ciudadano y la política. Ello otorga al periodista político no solo poder, sino que lo hace comprometerse a ejercer su trabajo de manera responsable y profesional para generar un público no solo receptivo sino también activo en la esfera pública (Robledo-Dioses, 2017).

\section{El trabajo del periodista político}

Es este el contexto mediático en el que buscaremos estudiar los recursos y constreñimientos que los periodistas políticos afrontan al interior de las empresas informativas. Para explicarlo, resulta útil describir cómo realizan su trabajo.

El periodismo político, como señala Andreu Casero-Ripollés, es la práctica infor- institucional como de la extrarrepresentativa. En ese sentido, aborda, de un lado, la actividad de los gobiernos, los partidos y las organizaciones políticas, las campañas políticas, las elecciones $\mathrm{y}$, de otro lado, las protestas, las manifestaciones, las acciones de los movimientos sociales o de la sociedad civil en el plano político; en fin, todos aquellos acontecimientos que estén relacionados con la res pública. (Casero-Ripollés, 2012).

Robledo Dioses (2017) anota que el periodismo político es un tipo de actividad periodística especializada que emplea tres tipos de fuentes: las institucionales, es decir, la instituciones políticas representadas por los tres poderes del Estado; los partidos políticos; y las instituciones no políticas, que si bien no están conformadas por la voluntad popular, pueden jugar un papel importante en el ámbito político, como iglesias, gremios empresariales y Organizaciones No Gubernamentales (ONG). A todas ellas, habría que sumar a los organismos constitucionales autónomos, como son los organismos electorales, el Tribunal Constitucional, la Contraloría General de la República, el Ministerio Público, etc.

La relación entre el periodista político y las fuentes informativas depende de la capacidad de agenda del periodista y del acceso personalizado a las fuentes informativas, muy especialmente a los actores políticos. Así pues, la capacidad del periodista para conseguir información se basa en la 
confianza que pueda desarrollar con el político o la fuente. Para ello, resulta útil al periodista tener una relación personal con el político (Saperas Lapiedra, 2013).

En las rutinas del periodista político al interior de empresas informativas como "Universo", es posible distinguir tres procesos. El primero de ellos es la cobertura o reporteo, que puede ser definido como el conjunto de actividades que realiza el periodista para conseguir la información que necesita a fin de elaborar contenido periodístico que demandan la coyuntura, sus editores o que son producto de sus propio iniciativa y agencia: entrevistar a especialistas o testigos, conversar con los personajes involucrados en la noticia, acudir a conferencias de prensa o sesiones parlamentarias, obtener documentos, buscar archivos periodísticos o recoger cualquier tipo de información que el periodista considere necesaria. El segundo de estos procesos es la elaboración del contenido periodístico en sí, es decir, la redacción de la nota periodística concreta y de algún otro complemento que pueda acompañar la nota periodística (infografía, video, etc.). Y el tercer proceso es la edición, en el cual el contenido periodístico es sometido a corrección, revisión y deliberación por parte del editor, editores e incluso del director.

\section{Recursos materiales}

Ahora bien, para que este trabajo se lleve a cabo de una manera óptima (que la teoría del periodismo llama calidad periodística o journalistic quality), resultan necesarias ciertas condiciones, como los recursos materiales. Winfried Schulz (2017) define estos recursos como los requerimientos básicos para que los periodistas puedan realizar su trabajo, como presupuesto, equipo técnico, computadoras, sistemas de comunicación, infraestructura en general, así como la disponibilidad de personas que sean talentosas y bien preparadas para el periodismo.

En el caso que estamos estudiando, los periodistas entrevistados, a pesar de ser jóvenes, han tenido experiencia de trabajo en otras empresas informativas, obviamente, todas ellas más modestas que el poderoso "Universo".

En sus trabajos anteriores, por ejemplo, utilizaban los teléfonos celulares que ellos mismos solventaban. Además, en aquellas redacciones el uso del teléfono fijo tenía restricciones de tiempo: la llamada se cortaba luego de unos pocos minutos. Es más, en uno de los casos, había un solo teléfono fijo para toda la redacción.

En cambio, en "Universo", cada uno tiene un teléfono celular que la empresa le ha asignado de manera gratuita. Además, en sus escritorios tienen teléfonos fijos con los cuales pueden llamar sin limitación de tiempo a teléfonos fijos o celulares: eso sí, cada uno tiene una clave de acceso que la empresa les ha brindado. Cabe recalcar 
en este punto que la comunicación "sin cortes" es muy importante para los periodistas, pues les permite contactar a las fuentes que les otorgarán la información necesaria para realizar el trabajo.

El transporte también es importante para los periodistas, pues les permite desplazarse a fin de contactar a sus fuentes o acudir a los lugares donde ocurren los eventos noticiosos. Para ello, en "Universo" pueden solicitar que los traslade alguno de los automóviles que la empresa posee. Si no hubiera algún vehículo disponible, pueden tomar un taxi, ya sea para ir al destino o para regresar. El monto que hayan gastado les será inmediatamente repuesto con la presentación de una declaración jurada firmada por el editor de la sección ${ }^{1}$. En sus trabajos anteriores, en cambio, debían esperar a que haya alguna movilidad para ir o para volver de sus destinos, o, caso contrario, costearse su propio desplazamiento.

Además, cada uno dispone en "Universo" de una desktop con conexión a Internet de banda ancha, lo cual les permite buscar información y escribir sin muchas complicaciones. El recuerdo de "Jessica" sobre su anterior trabajo es ilustrativo sobre la diferencia en los recursos materiales:

Había mucho más trabajo. Hacíamos todo, todos: grabar videos, editar. Acá estoy más relajada. Era muy po- bre allá, porque éramos poquitos y ahí nos arreglábamos con las computadoras. Yo pedía que me compraran una computadora, porque teníamos laptops que no funcionaban.

\section{Constreñimientos en las empresas informativas}

Sin embargo, además de brindar recursos materiales a los periodistas políticos, las empresas informativas también ejercen ciertos constreñimientos o limitaciones a su trabajo. Pierre Bourdieu (1997) señala que en los medios de comunicación existe una "censura invisible", definida como la pérdida de la autonomía, tanto del medio de comunicación como del periodista. La autonomía de los medios de comunicación se puede ver afectada debido a la necesidad que tienen de obtener ingresos de la publicidad o de subvenciones del Estado. La autonomía del periodista se puede ver afectada por el grado de concentración de la prensa (en un contexto de concentración, los periodistas que salen de un conglomerado ven reducidas sus posibilidades de conseguir un nuevo empleo), por la posición del medio de comunicación donde labora, por la posición del periodista en el medio de comunicación y por su capacidad de producción autónoma de información.

Esta censura invisible tiene dos dimensiones: de un lado, encontramos la "censura 
política”, que se impone a los periodistas como un control político a través de los nombramientos de cargos directivos en la empresa informativa; de otro lado, tenemos las “censuras económicas”, que consisten en la coerción económica de propietarios, anunciantes o del Estado (Bourdieu, 1997).

Por su parte, Pedro Antonio Rojo Villada (2003) también señala que el trabajo de los periodistas recibe dos tipos de presiones: externas e internas. Externamente, esta presión es ejercida por la audiencia, a la que se busca atraer para conseguir publicidad; las fuentes, que proporcionan la materia prima informativa; y los grupos de presión, tales como anunciantes, partidos políticos, gobiernos, etc., que tratan de interferir en la política informativa de cualquier medio de comunicación. Internamente, encontramos que los medios de comunicación son empresas con las mismas limitaciones económicas y técnicas que el resto de empresas, donde los periodistas son simples asalariados en una estructura burocrática y jerarquizada como cualquier otra.

Siguiendo el marco de análisis propuesto por Bourdieu y Rojo Villada, podemos proponer dos tipos de limitaciones o constreñimientos que afectan el trabajo de los periodistas políticos en las empresas periodísticas.

- Constreñimientos corporativos. Estas limitaciones están relacionadas con la naturaleza empresarial capitalista del medio de comunicación. Como toda empresa, es necesario cumplir con ciertos requisitos de producción cuantificable y que dicha producción sea la mayor posible, al mismo tiempo que represente el menor costo probable. Asimismo, en tanto empresa, hay propietarios o accionistas cuyos intereses pueden afectar el desarrollo del trabajo de los periodistas políticos.

- Constreñimientos editoriales. Estas limitaciones reciben este nombre porque son impuestas por los editores y porque suelen justificarse en supuestos principios editoriales. Se trata de las interferencias que los periodistas padecen en su trabajo a fin de que inclinen sus contenidos a favor de determinados personajes políticos o en contra de otros, lo cual tiene su origen en ciertas preferencias o simpatías políticas.

A continuación, explicaremos cada uno de los dos tipos de constreñimientos, apoyándonos para ello en los testimonios obtenidos a través de las entrevistas.

\subsection{Constreñimientos corporativos}

\subsubsection{Taylorismo informativo $y$ escasez de tiempo}

El gran capital ha buscado siempre optimizar sus procesos productivos, para 
lo cual ha recurrido a la administración científica, empleando los postulados de Frederick Talyor. Estos asumen que existe flojera $\mathrm{u}$ holgazanería, provenientes del instinto natural a tomar las cosas con calma. Así, el capital consideraba que los obreros, controlados tan solo por órdenes y disciplina generales, no estaban lo suficientemente controlados, pues mantenían cierta iniciativa sobre qué hacer con el trabajo (Braverman, 1978).

En la era del Internet, los principios de Taylor han alcanzado también a las empresas informativas. La teoría del periodismo ha definido esta situación como "taylorismo informativo". Este término define un escenario en el que los medios de comunicación enfrentan la necesidad de inmediatez y la escasez de recursos, mientras los periodistas desarrollan su trabajo sometidos a una presión constante y deben emitir contenidos en tiempo real y con una casi inexistente labor de recolección de información (Munive, 2006).

Como toda empresa informativa, "Universo” busca atraer cada vez más lectores para su plataforma online web, lo cual le permitiría convertirla en un medio de comunicación cada vez más atractivo para los anunciantes. Esta pretensión corporativa ha llevado a la empresa a implementar decisiones que le permitan contabilizar la producción de los periodistas.
En primer lugar, los editores pueden saber cuántas notas para la plataforma online ha elaborado cada periodista. En segundo lugar, conocen cuántas visitas reciben cada una de ellas. En tercer lugar, a través de un software llamado Charbeat, son capaces de conocer en tiempo real cuántos usuarios están leyendo la nota y cuánto tiempo permanecen en la página. Adicionalmente, colocan metas a cada equipo periodístico. La sección política de "Universo", por ejemplo, tenía como meta en junio del 2017 alcanzar los ocho millones de páginas vistas².

En febrero del 2017, debido a los desastres producidos por el fenómeno de El Niño, la sección política alcanzó el récord de 12 millones de páginas vistas. "La meta del mes siguiente fue más. Obviamente, no la superamos", relata uno de los periodistas entrevistados, y explica que esos picos en el tráfico siempre se deben a una coyuntura específica que despierta un singular interés del público por determinados temas.

Por eso "Andrés" acusa una "falta de comprensión" de parte de quienes establecen estas metas, pues se rigen por un criterio que no necesariamente se corresponde con la realidad de la coyuntura. "No es que haya una fórmula en ese momento para que esas personas entren a la web. Es que ocurrió algo en el mundo exterior que los hace entrar, pero (...) es imposible que se replique”, añade. 
Y ante la dificultad de alcanzar metas más altas cuando no hay nada que justifique el aumento de las visitas al sitio web de "Universo", los periodistas políticos se ven forzados a elaborar contenido que ellos consideran de poca calidad periodística, pero que atrae audiencia. "Francisco" lo explica de esta manera: "Hay dos criterios generales que un periodista evalúa: el criterio periodístico como tal, lo que nosotros quisiéramos conocer, los baluartes del periodismo, que deben ser la objetividad, la veracidad, la libertad. Y después está lo que vende”.

"Gabriel” también critica esta métrica que les es impuesta, y considera que el Charbeat "forma parte de esta dictadura de clic". "Creen que a medida que un periodista publicaba más notas, es más eficiente. Pero si te das cuenta, en esa ecuación no está la calidad informativa. Esa ecuación es cantidad".

Y en este escenario de control el bien más preciado para los periodistas es el tiempo, el cual siempre es escaso. Como señala Jornet (2006, p.81): "El periodismo es una tarea que se realiza apremiada por el tiempo. Y ello obliga a un esfuerzo de gestión importante, y muchas veces condiciona o altera los planes de calidad".

Precisamente por esta permanente carencia de tiempo, "Jessica" señala que a veces le incomoda que los editores no entiendan que para que un trabajo sea de calidad se necesita tiempo, pues las fuentes no responden de un día para otro. Además, escribir una nota, más aún si se busca "algo más acronicado", requiere de tiempo. "A veces [los editores] no entienden mucho del proceso para elaborar una nota. [...] Te ponen plazos. Los vas a cumplir, pero el producto no va a ser como debería”, relata "Jessica”.

Esta falta de tiempo también es razón para que los periodistas no propongan las notas que les gustaría escribir, las cuales suelen ser de largo aliento y requieren de varias fuentes. Sin embargo, pareciera que se resignan o se conforman con hacer lo que ellos llaman "notas del día". "Andrés" cuenta que ya ni siquiera propone hacer notas sobre las que le gustaría escribir:

En mi caso yo estoy dedicado a las noticias diarias, ya sea desde la redacción o saliendo al Congreso. Es bien limitado el tiempo que tengo, no tengo ni siquiera un horario fijo de chamba: las ocho horas son un mito.

Por su parte, "Francisco", quien dice que su trabajo está más dedicado a la plataforma online, explica que muchas veces la nota periodística debe ser elaborada de inmediato para que "Universo" sea el primer medio en informar sobre cualquier asunto importante y sorpresivo. Por esta

3 Un estilo "acronicado" es propio de la crónica, que es el género periodístico en cuya redacción se emplean más recursos literarios. 
razón "Francisco" se siente como atado a su silla y escritorio. En sus palabras:

No puedo alejarme mucho tiempo de mi sitio físico porque se me necesita en un determinado lugar y momento del día. Y eso evita que esté en los lugares donde ocurre la noticia. Es un poco frustrante, eso es lo que no permite que pueda hacer un mejor trabajo.

\subsubsection{Injerencias de los propietarios}

Al hablar del modelo de propaganda que existe en los sistemas democráticos, Noam Chomsky y Edward S. Herman enfatizan que el incremento de escala de la empresa periodística ha generado que casi la totalidad de los medios de comunicación estén en manos de los grandes grupos económicos. De esta manera, las empresas dominantes en el campo de la comunicación son grandes negocios, controlados por personas muy poderosas o por directivos sometidos a severas limitaciones por parte de los propietarios $\mathrm{y}$ otras fuerzas orientadas hacia los beneficios del mercado, estrechamente unidas y con importantes intereses comunes con otras grandes empresas, con los bancos y/o con el gobierno (Chomsky y Herman, 1995).

En el contexto peruano, un caso bastante estudiado es el del Grupo El Comercio, el más importante conglomerado mediático te literatura documentada referida a las presiones que se ejercen sobre editores y directores, tanto desde fuera como desde dentro de la organización.

En un extenso trabajo de investigación académica, José Alejandro Godoy expone un conjunto de episodios en los que los editores del diario El Comercio son sometidos a una serie de presiones por motivos comerciales o políticos, las cuales suelen ejercerse a través del directorio de accionistas (Godoy Mejía, 2019).

En un extenso trabajo de investigación periodística, Marco Sifuentes también cuenta cómo durante el gobierno de Ollanta Humala, su esposa, Nadine Heredia, ejerció -a través de miembros de la familia Miró Quesada- una serie de presiones, mediante llamadas y mensajes, para evitar que se publique una entrevista que le había hecho la revista Cosas, en la cual daba declaraciones políticas de las que luego se arrepintió (Sifuentes, 2018).

Desde el género de las memorias, Maki Miró Quesada, integrante de la familia que controla el Grupo El Comercio, cuenta ella misma cómo ejerció presión en el directorio de la empresa, el cual integraba, para remover de su cargo al director periodístico del diario El Comercio, Fernando Berckemeyer, por haber tomado decisiones editoriales con las que ella estaba en desacuerdo (Miró Quesada, 2018). 
Estos casos nos llevan a señalar que el hecho de que las empresas informativas tengan como propietarios o accionistas a hombres y mujeres de negocios dedicados a otras actividades empresariales, con intereses políticos y comerciales distintos al interés periodístico, hace que los periodistas estén sometidos a lo que denominamos constreñimientos corporativos.

Un ejemplo de este tipo de limitaciones fue mencionado en una de las entrevistas. Resulta que uno de los accionistas de "Universo" lo es también de una empresa constructora que se ha visto involucrada en un caso de corrupción que remese a varios países de América Latina ${ }^{4}$.

Una de las personas entrevistadas para este trabajo relató que los editores le pidieron que hiciera una nota periodística que criticara un proyecto de ley que una congresista de Fuerza Popular había presentado con el fin de que recaiga responsabilidad penal sobre la empresa constructora del mencionado accionista. De acuerdo al relato, este pedido no tenía una motivación de índole periodística, pues el hecho carecía de ciertas características noticiosas. Cuenta quien hizo la nota: "No había más historia en el asunto. Me hicieron hacer la nota, que es un tema que yo no sigo. (...) Era un proyecto recién presentado, no me pareció que tenía tanta historia. Hice la nota, pero no estuve tan cómodo".

\subsection{Constreñimientos editoriales}

Los medios transmiten gran cantidad de información respecto a la cual el público busca orientación. Cuando los medios ejercen la función de establecimiento de agenda, seleccionando temas y silenciado otros, determinan la importancia y prioridad que cada uno tiene en la agenda pública, y así, a través de la presencia selectiva, repetida, constante y pública, orientan la atención de la opinión pública (Monzón, 2006).

Y por medio del uso selectivo de las fuentes, la rutina del ritmo de las noticias y la selección de temas, los medios noticiosos deciden qué actores estarán representados públicamente, qué se dirá de ellos y, especialmente, cómo se dirá. Pero estos procesos de producción de noticias no son arbitrarios y no están determinados únicamente por el interés periodístico, sino que responden a criterios ideológicos y profesionales que otorgan el acceso preferencial a determinadas personas y organizaciones (Sánchez García, 2010).

Habitualmente, se dice que estos criterios responden a la línea editorial de cada medio de comunicación. Pero Concha Edo (1994) señala que los principios editoriales son un conjunto de conocimientos determinados que inspiran los contenidos informativos y fundamentan la actividad empresarial, pero de ninguna manera son

4 La empresa en mención participó en consorcios junto a una empresa brasileña que, se ha probado, sobornó a autoridades peruanas para adjudicarse importantes obras de infraestructura. 
una corriente ideológica de tipo político o económico (Edo, 1994).

Lo cierto es que en la selección de temas que hacen, en el tratamiento que se dan, en la importancia otorgada a cada uno y en la presentación formal de los contenidos, se manifiestan claramente no solo la línea editorial, sino también la tendencia ideológica de cada medio (Davara Torrego, López Raso, Martínez-Fresneda Osorio y Sánchez Rodríguez, 2004). Y es que, a la hora de hacer su trabajo, los medios de comunicación, en conjunto, no son neutrales: los medios corporativos son fundamentalmente un negocio, y persiguen no solo intereses empresariales, sino también intereses políticos más amplios (Castells, 2009).

En este trabajo hemos llamado constreñimientos editoriales a aquellas injerencias de carácter político o ideológico que actúan sobre el trabajo de los periodistas políticos. Estas limitaciones son concretadas por los editores, que ocupan altos cargos en la burocracia periodística de la empresa informativa, y que siguen una supuesta línea editorial.

A juzgar por las entrevistas realizadas para este trabajo, las elecciones generales del 2016 fueron un escenario en el que los constreñimientos editoriales se hicieron sentir con cierta frecuencia. Los periodistas coinciden en señalar que, por un lado, había un interés en publi- los candidatos presidenciales de Alianza para el Progreso del Perú, César Acuña, y del Frente Amplio, Verónika Mendoza, y, por otro lado, había "una evidente inclinación” por el candidato de Peruanos por el Kambio, Pedro Pablo Kuczynski (PPK), un hombre identificado con la derecha, el empresariado y el mercado.

"En la campaña electoral era bastante complicado escribir acerca del Frente Amplio y Verónika Mendoza porque la línea editorial no ve con buenos ojos la participación de ellos en política. Es algo escandaloso", señala "Francisco".

"Había un requerimiento, a veces expreso y a veces tácito, de que había que tratar a los candidatos de diferente manera", agrega "Andrés". Él recuerda que, si bien durante la campaña Kuczynski tuvo declaraciones desafortunadas en varias ocasiones, no se le prestaba la misma atención a sus yerros en comparación a los de Verónika Mendoza o de algún allegado suyo.

Siendo Verónika Mendoza una política de izquierda, estos episodios no deberían sorprender. Como señalan Chomsky y Herman (1995, p.68), uno de los filtros del sistema de censura invisible es el anticomunismo, el cual funciona como un medio de control. El comunismo, en tanto implica regímenes autoritarios, ha sido siempre considerado el peor de los males. Pero también es el peor enemigo de los empresarios y propietarios, ya que 
amenaza su posición de clase y su estatus superior. Así pues, la oposición al comunismo se ha convertido en una de las principales banderas de la ideología occidental. Esta ideología del anticomunismo permite a la población movilizarse contra un enemigo, y dado que es un enemigo difuso, puede ser utilizado contra cualquiera que propugne los intereses de la propiedad (Chomsky y Herman, 1995).

Otro episodio similar se produjo cuando a "Francisco" le pidieron elaborar con prisa una nota en base a una información según la cual uno de los candidatos del Frente Amplio al Congreso había pertenecido a organizaciones simpatizantes de Sendero Luminoso. Sin embargo, "Francisco" pidió que se le diera cierto tiempo para al menos llamar a la persona involucrada, uno de los principios de equidad más básicos del periodismo. "Pero hubo presión, hubo presión. Y aun así intenté comunicarme con él. Lo logré después. Pero la discusión ya se había desatado. Hubo molestias de parte de mis superiores”, relata.

Las limitaciones al trabajo de los periodistas durante la campaña electoral del 2016 no solo se presentaron en torno a la cobertura de Verónika Mendoza. César Acuña también era un candidato que había conseguido desplazar en las preferencias electorales a Pedro Pablo Kuczynski. Pronto, sin embargo, se ciñeron sobre Acuña denuncias de plagio en sus tesis universitarias y en un libro publicado. En
"Universo" había interés por mantener este tema en agenda.

"Jessica" cuenta que se sintió presionada en este sentido, pues los editores le pidieron que siguiera haciendo notas sobre los plagios académicos que cometió César Acuña, a pesar de que ella pensaba que ya no había nada nuevo que contar y que un principio del periodismo consiste precisamente en publicar únicamente el contenido novedoso. "Ya habíamos agotado todo. Podía haber alguna que otra cosita, pero no eran cosas fuertes. Yo no consideraba [necesario hacer una nota], pero ellos me dijeron que sí, que sí, que sí. Al final, lo hice. No firmé la nota”, explica, aludiendo a uno de los pocos recursos que los periodistas tienen para expresar su desacuerdo con las imposiciones editoriales que sus jefes les aplican: retirar sus nombres como autores de la nota.

Este tipo de constreñimientos no solo se aprecian en época de campaña electoral. En el caso que estamos estudiando, las limitaciones prosiguieron cuando Pedro Pablo Kuczynski ya había ocupado la presidencia de la República. A poco de iniciado su gobierno, "Gabriel” obtuvo documentos que demostraban que Kuczynski había ocultado información sobre su patrimonio en la declaración jurada que presentó al Jurado Nacional de Elecciones (JNE) como candidato presidencial. “[Los editores] me dijeron: 'Oye, mira, ¿sabes qué?, este gobierno 
recién está empezando. Hay que tratar de no pegarle, hay que darle un margen de maniobra", cuenta "Gabriel", quien insistió argumentando que era necesario que la ciudadanía sepa que Kuczynski no había dado toda la información sobre su patrimonio. "La respuesta [que me dieron] fue que PPK no estaba obligado a hacerlo”, agrega “Gabriel”.

Como afirma Castells (2009), los medios corporativos tienen intereses políticos en tanto se encuentran directamente implicados en la dinámica del Estado, que es una parte fundamental de su entorno empresarial. Esto los lleva a producir mensajes que estén en consonancia con sus intereses profesionales y empresariales, $y$ a acallar otro tipo de informaciones.

A fines de mayo del 2017, "Francisco" estaba a punto de escribir para la plataforma online una nota sobre unas duras declaraciones que el entonces contralor general de la República, Édgar Alarcón, había lanzado contra el entonces ministro de Economía y Finanzas, Jaime Thorne. "Francisco" consideraba que el asunto era noticioso. Sin embargo, le dijeron que no lo haga. "No se quería publicar esta declaración porque ya había supuestamente una nota anterior. Pero esta brindaba unos elementos nuevos", dice "Francisco". "El medio no está confrontando al gobierno como, asumo, debería hacerlo. Estamos siendo condescendien- tes con el gobierno y eso no me parece lo más adecuado", añade.

"Andrés" también cuenta que tuvo una discusión con su editor por una nota relacionada a unas declaraciones que Pedro Pablo Kuczynski dio en Estados Unidos. El entonces mandatario dijo que América Latina era "como un perro simpático que duerme en la alfombra y no causa problemas a nadie" 5 . Sin embargo, su editor le aseguraba que en realidad Kuczynski había empleado una expresión usual en inglés, razón por la cual le indicó que el titular solo mencionara que PPK había dicho que América Latina era para Estados Unidos "un perro que no da problemas". En este caso, puede pensarse que los editores temían que un titular más apegado a los hechos afectara de manera negativa la imagen del presidente de la República.

\section{A modo de conclusión: un periodismo político menos profundo}

Si bien es cierto que el periodista político encuentra en las empresas informativas una serie de recursos materiales que le facilitan el trabajo, también es innegable que la naturaleza corporativa de los medios informativos trae consigo una serie de injerencias en el trabajo de los periodistas. La información política que se produce en estos medios de comunicación no responde exclusivamente a la necesidad

5 La expresión de Kuczynski en inglés fue: "It's like a nice dog sleeping on the carpet there. It's no causing anybody any problems". Ver: https://bit.ly/2XzFQ6N 
de tener una opinión pública debidamente informada, sino que también persigue intereses económicos y políticos. Ello dificulta que la ciudadanía disponga de información política de calidad.

Los periodistas entrevistados dicen que les gustaría hacer notas mejor elaboradas, de mayor profundidad, de más largo aliento, pero los constreñimientos que hemos analizado en este artículo les dificultan este trabajo. En un entorno mediático en el que hay cierta desesperación por atraer audiencias y anunciantes, lo inmediato y lo trivial acaba predominando.

"Andrés" calcula que el $60 \%$ de su producción periodística son "notas periodísticas simples, del día, ya sea para el papel o para la web, sin más análisis que la coyuntura”. Él quisiera hacer notas que le permitan mirar más allá de la coyuntura y hacer un análisis más profundo de los hechos políticos. Sin embargo, asegura que no le son confiadas tales responsabilidades.

“Gabriel” también asegura que le gustaría hacer notas de mayor profundidad, como explicar, por ejemplo, cuáles fueron los factores que permitieron que la empresa constructora brasileña de la que hablamos líneas arriba haya podido extender su red de corrupción en el Perú. "Pero eso demanda tiempo, demanda ejercicio, demanda un espacio bueno para poder contarlo, pero es imposible, no te lo van a dar. Nos hemos quedado en el qué, quién, pasó esto, pasó aquello, punto cerrado", asegura.

"Francisco" señala que, como debe elaborar notas del día para el portal web de "Universo", está obligado a permanecer en la redacción. Esto le impide estar en las sedes de poder donde se producen los hechos noticiosos políticos, como Palacio de Gobierno, el Palacio Legislativo o Palacio de Justicia, espacios donde podría tener contacto personal con las fuentes. Esto le permitiría tener acceso a información con la cual podría elaborar contenido periodístico de mejor calidad. "Eso sí es algo que me frustra bastante. Debe ser el punto en el cual yo me siento más disminuido laboralmente”, dice.

De lo expuesto hasta este punto se puede colegir que la naturaleza corporativa de las empresas informativas, que persiguen intereses comerciales o políticos ajenos al interés periodístico, dificultan el trabajo de los hombres y mujeres dedicados a elaborar informaciones políticas. Ello supone, en menor o mayor medida, un riesgo para el sistema democrático, en el cual se supone que debe haber una ciudadanía debidamente informada sobre asuntos públicos, en general, y asuntos políticos, en particular. Pero, sin periodistas políticos cuya autonomía no sea respetada, este principio democrático será inalcanzable. 


\section{REFERENCIAS}

Becker, H. S. (2008). Los mundos del arte: Sociología del trabajo artístico. Quilmes: Universidad Nacional de Quilmes.

Bourdieu, P. (1997). Sobre la televisión. Barcelona: Anagrama.

Braverman, H. (1978). Trabajo y capital monopolista. México D.F.: Nuestro Tiempo.

Campos-Freire, F.; Yaguache, J. y Ulloa, N. (2017). Tendencias de la industria de los medios de América del Sur en la transición digital. Revista de Comunicación, 16 (2), 33-59. https://doi. org/10.26441/RC16.2-2017-A2

Carrillo, N. (2013). El periodismo volátil. ¿Cómo atrapar la información política que se nos escapa? Barcelona: UOC.

Casero-Ripollés, A. (2012). El periodismo político en España: algunas características definitorias. En A. Casero-Ripollés (Eds.), Periodismo político en España: concepciones, tensiones y elecciones (pp. 21-48). Tenerife: Sociedad Latina de Comunicación Social.

Castells, M. (2009). Comunicación y poder. Madrid: Alianza Editorial.

Chomsky, N. y Herman, E. S. (1995). Los guardianes de la libertad: propaganda, desinformación y consenso en los medios de comunicación de masas. Barcelona: Grijalbo Mondadori.

Conaghan, C. (1997). Vida Pública en los tiempos de Alberto Fujimori. En F. Tuesta Soldevilla (Ed.), Los Enigmas del Poder. Fujimori 1990-1996 (pp. 303-329). Lima: Fundación Friedrich Ebert.

Davara Torrego, J.; López Raso, P.; Martínez-Fresneda Osorio, H. y Sánchez Rodríguez, G. (2004). España en portada. Análisis de las primeras pá- ginas de los diarios nacionales y su influencia en la sociedad. Madrid: Fragua.

Díaz Nosty, B. (2017). 2007-2017: Disrupción en el sistema de medios: Coexistencia generacional de diferentes prácticas de comunicación. En B. Díaz Nosty (Ed.), Diez años que cambiaron los medios: 2007-2017 (pp. 7-87). Madrid: Ariel, Fundación Telefónica.

Edo, C. (1994). La crisis de la prensa diaria. La línea editorial y la trayectoria de los periódicos de Madrid. Barcelona: Ariel Comunicación.

Fine, G. A. (1992). The Culture of Production: Aesthetic Choices and Constraints in Culinary Work. American Journal of Sociology, 97 (5), 1268-1294. https:// doi.org/10.1086/229902

Godoy Mejía, J. A. (2019). El Comercio y la política peruana del siglo XXI: pugnas entre liberales y conservadores detrás de las portadas. Lima: Instituto de Estudios Peruanos (IEP).

Jornet, C. (2006). Gestión periodística. Herramientas para lograr un periodismo efectivo y de calidad. Buenos Aires: Prometeo.

Lippmann, W. (2003). La opinión pública. Madrid: Langre.

López García, X. (2010). La metamorfosis del periodismo. Sevilla: Comunicación Social.

McQuail, D. (1996). Introducción a la Teoría de la Comunicación de Masas. México D.F.: Paidós.

Mellado-Ruiz, C.; López-Rabadán, P. y Elortegui, C. (2017). ¿(Para) ciudadanos o espectadores? Periodismo político chileno y sus modelos profesionales de aproximación a la audiencia. $\mathrm{Pa}$ - 
labra Clave, 20 (1), 14-46. https://doi. org/10.5294/pacla.2017.20.1.2

Miró Quesada, M. (2018). Memorias de una transgresora. Lima: Melquiades.

Monzón, C. (2006). Opinión pública, comunicación y política. Madrid: Tecnos.

Munive, M. (2006). Periodismo de declaraciones. Cuando la prensa renuncia a ser el lugar de los hechos. Conexión, (6), 42-57.

Nafría, I. (2017). La reinvención de The New York Times. Austin: Centro Knight para el Periodismo en las Américas de la Universidad de Texas.

Robledo-Dioses, K. (2017). Periodismo político: una aproximación al rol social de la profesión y su relación con la democracia. Revista Científica de Comunicación, 8 (2), 22-32.

Rodrigo Alsina, M. (1993). La Construcción de la Noticia. Barcelona: Ediciones Paidós.

Rojo Villada, P. A. (2003). Tecnología y contextos mediáticos. Condicionamientos socioeconómicos y políticos de la comunicación de masas en la Sociedad de la Información. Sevilla: Comunicación Social Ediciones y Publicaciones.

Sánchez García, F. M. (2010). Pragmática de los titulares políticos: Las estrategias implícitas de persuasión ideológica. Madrid: Visor Libros.

Saperas Lapiedra, E. (2013). Periodismo político e Internet: El impacto de la innovación tecnológica en las rutinas periodísticas en los medios de comunicación de referencia en España. En A. Casero-Ripollés (Ed.), Periodismo político en España: concepciones, tensiones y elecciones (pp. 69-84). Tenerife: Sociedad Latina de Comunicación Social.
Schulz, W. (9 de julio del 2017). Preconditions of Journalistic Quality in an Open Society. Recuperado de https://bit. ly/2JpxK89

Sifuentes, M. (2018). H\&H: Escenas de la vida conyugal de Ollanta Humala y Nadine Heredia. Lima: Planeta.

Tallón, J. (1992). Lecciones de empresa informativa. Madrid: Ediciones de las Ciencias Sociales.

Organización de las Naciones Unidas para la Educación, la Ciencia y la Cultura (Unesco). (2018). Tendencias mundiales en libertad de expresión y desarrollo de los medios: 2017/2018. París: Unesco.

Valera García, S. J. (2016). Influencia de la crisis de las empresas periodísticas en la calidad informativa. Madrid: Universidad Complutense de Madrid. 